\title{
The assessment of general movements in term and late-preterm infants diagnosed with neonatal encephalopathy, as a predictive tool of cerebral palsy by two years of age - A scoping review.
}

Judy Seesahai

Sunnybrook Health Sciences Centre

Thomas Rotter

Queen's University

Maureen Luther

Sunnybrook Health Sciences Centre

Patricia Maddalena

Sunnybrook Health Sciences Centre

Paige Terrien Church

Sunnybrook Health Sciences Centre

Elizabeth Asztalos

Sunnybrook Health Sciences Centre

Rudaina Banihani ( $\square$ rudaina.banihani@sunnybrook.ca )

Sunnybrook Health Sciences Centre https://orcid.org/0000-0002-3865-3045

\section{Research}

Keywords: Neonatal encephalopathy, general movement assessment, Prechtl, hypoxia-ischemia encephalopathy, cerebral palsy, infants/neonates, term babies, preterm babies, motor development

Posted Date: January 11th, 2021

DOI: https://doi.org/10.21203/rs.3.rs-59512/v2

License: (c) (i) This work is licensed under a Creative Commons Attribution 4.0 International License. Read Full License

Version of Record: A version of this preprint was published at Systematic Reviews on August 12th, 2021. See the published version at https://doi.org/10.1186/s13643-021-01765-8. 


\section{Abstract}

BACKGROUND The General Movements Assessment is a non-invasive and cost-effective tool with demonstrated reliability for identifying infants at risk for cerebral palsy. Early detection of cerebral palsy allows for implementation of early intervention, and is associated with better functional outcomes. No review to date has summarized the utility of the General Movements Assessment to predict cerebral palsy in term and late-preterm infants diagnosed with neonatal encephalopathy.

METHODS We conducted a scoping review involving infants born greater than or equal to 34 weeks gestational age to identify all available evidence and delineate research gaps. We extracted data on sensitivity, specificity, positive and negative predictive value and described the strengths and limitations of the results. We searched five databases (MEDLINE, Embase, PsychINFO, Scopus and CINAHL). Two reviewers conducted all screening and data extraction independently. The articles were categorized according to key findings and a critical appraisal performed.

RESULTS From the electronic database search, only two studies, case series, met all of the inclusion criteria. The total number of participants were 60. Neither of the final eligible studies included late-preterm neonates. Both studies reported on sensitivity, specificity, positive predictive and negative predictive value. The newer study reported that in the time period between term and 4-5 months post-term, that any cramped synchronized movements in this time period had results of $100 \%$ sensitivity and variable results for specificity, positive predictive value and negative predictive value. Neither of the studies had infants that received therapeutic hypothermia for Neonatal Encephalopathy.

CONCLUSIONS The finding of cramped synchronized General Movements is a strong predictor for the diagnosis of cerebral palsy by two years of age in the term population with neonatal encephalopathy. The deficit of high quality research limits the applicability and so the general movements assessment should not be used in isolation when assessing this population.

\section{Systematic review registration}

Title registration with Joanna Briggs Institute. URL: http://joannabriggswebdev.org/research/registered_titles.aspx

\section{Background}

Prediction of long-term neurodevelopmental outcomes remains an elusive goal for neonatology. Clinical and socioeconomic markers have not proven to be as reliable as we have hoped ${ }^{1,2}$. The limitation in prognostication is particularly challenging for those term and late-preterm infants born with neonatal encephalopathy (NE).

NE describes those infants born with an atypical neurological exam and is by definition heterogeneous in etiology ${ }^{3}$. The specific etiology may not be clear for months to years later but the presentation is characterized by central nervous system disruption ${ }^{4}$ and is associated with an increased risk for long-term neurodevelopmental challenges including cerebral palsy (CP). Infants presenting with NE are managed now with therapeutic hypothermia as the standard of care; this is presumptive management, and is time sensitive should the etiology be hypoxia/ischemia (Hypoxic Ischemic Encephalopathy (HIE)), in term and late-preterm infants ${ }^{4,5}$. Therapeutic hypothermia reduces the likelihood of challenging outcomes by containing any potential ongoing neurological injury. It does not, however, completely eradicate the possibility of long-term neurodevelopmental disability ${ }^{6}$.

For parents of infants affected by NE, the desire for accurate prognostication is of tantamount importance ${ }^{6,7}$. This information can guide decisions around early intervention and, in severe cases, withdrawal of care for those infants with severe involvement. For those infants that survive NE and are at increased risk for $\mathrm{CP}$, recent international recommendations now call for early detection and intervention of CP in order to improve functional outcomes $^{1,8,9}$. These recommendations are based on mounting evidence for better detection tools as well as the benefits of early intervention.

Historically, clinical and radiological predictors of neurological outcomes were used to classify the degree of NE. Severity scoring systems include the classical grading by Sarnat and Sarnat ${ }^{10}$ in 1976, to the newer scores by Miller et al. ${ }^{11}$ in 2004, with added parameters such as oral feeding difficulties and the presence of seizures. Radiologically, specific findings of diffusion restriction on magnetic resonance imaging (MRI) have been linked to later development of $\mathrm{CP}^{4}$. These predictors, however, were not sufficiently accurate ${ }^{1,2}$ and the high costs of imaging as well as shortages in access further restricts the utility. Neurological examinations have historically been limited in predictive value but recent emerging evidence with an observational tool, the General Movements Assessment (GMA) developed by Dr. Heinz Prechtl has demonstrated strong predictive value ${ }^{12,13}$.

The GMA is a non-invasive, cost-effective tool with demonstrated reliability for identifying infants at risk for neuromotor impairment ${ }^{14}$. General movements (GMs) are complex, highly variable, whole-body movements which emerge in the fetus and progress through an age-specific developmental trajectory, dissipating by the end of the first four to five months of life ${ }^{13}$. Developmental progression and variety, or lack thereof, are indicators of nervous system integrity and can reflect neurodevelopmental outcomes ${ }^{15}$. Cramped synchronized (CS) and absent fidgety movements are considered abnormal GMAs, demonstrating developmental stereotypy ${ }^{13}$. Additionally, the Motor Optimality Score (MOS) represents a more detailed quantitative analysis of the general movements motor repertoire of infants between 11 and 17 weeks post-term. The MOS has been shown to be predictive of the severity and type of Cerebral Palsy ${ }^{16,17}$. 
Several researchers have looked at the GMA from different aspects. We were interested in term and late-term preterm infants with NE and how the GMA may be useful in predicting CP. A preliminary search of PROSPERO, MEDLINE, the Cochrane Database of Systematic Reviews and the Joanna Briggs Institute (JBI) Database of Systematic Reviews and Implementation Reports was conducted to assess this research. There were two current systematic reviews on GMA, one in $2018^{18}$ and the other in $2017^{9}$. In addition, eight older reviews were identified: seven systematic reviews ${ }^{13,19-24}$ and one literature review ${ }^{25}$ done between 2001 to 2013 . The search also revealed three pending reviews identified around the topic of the predictive value of $\mathrm{GMA}^{26-28}$. These pending reviews were all systematic reviews.

The key characteristics and main findings of the above reviews on GMA are detailed in the protocol for this systematic review ${ }^{29}$ and is included in Table 1, Additional file 1. The two latest reviews were by Kwong et al. $2018^{18}$ and Novak et al. $2017^{9}$. In general, these reviews did not look specifically at the population we were interested in for this scoping review, that is, term and late-preterm infants with NE. Additionally, the other systematic reviews and literature review were all more than five years ago with the latest in $2013^{13}$. Thus, a gap exists in the literature to clearly identify the evidence for our population of interest.

The objective of this review is therefore, to identify the scope of the research with regards to the GMA and its ability to predict CP, in term and latepreterm infants with a diagnosis of $\mathrm{NE}$, and to identify the gaps in the literature.

\section{Objectives}

The primary research question for this review is: What is the published data on the predictive value of the GMA for the diagnosis of CP by two years of age in infants born at term or late-preterm presenting with NE?

The secondary research question is: What is the gap in the literature when the GMA is used to predict CP by two years of age in infants born at term or late-preterm presenting with NE?

\section{Methods}

\section{Study Design}

A scoping method was chosen for this type of review to fulfil our objective which requires searching and assessing a wide range of research methodologies involving the use of the GMA in CP prediction. A scoping review captured all types of relevant research on the topic in a systematic, transparent, rigorous and reproducible manner. This scoping review was conducted in accordance with the JBI methodology for scoping reviews ${ }^{40}$. The objectives, inclusion criteria and methods for this scoping review were detailed in advance and documented in a proposal (included as Additional file 2). The title of our review was registered with JBI. The protocol was published prior to this review ${ }^{39}$ (Additional file 1).

Inherent in the nature of the scoping review is the inclusiveness of a wide range of literature, and so we anticipated differences in the data quality. Critical appraisal and data synthesis therefore were challenging in terms of conclusive evidence as opposed to that from a systematic review. The scoping review methodology was however especially advantageous to our question as these types of reviews target areas that have not been comprehensively assessed before.

\section{Eligibility Criteria}

The participant, concept, context (PCC) framework for scoping reviews was used to define the review focus and is summarized in Table 2 below.(see Additional file 1). 


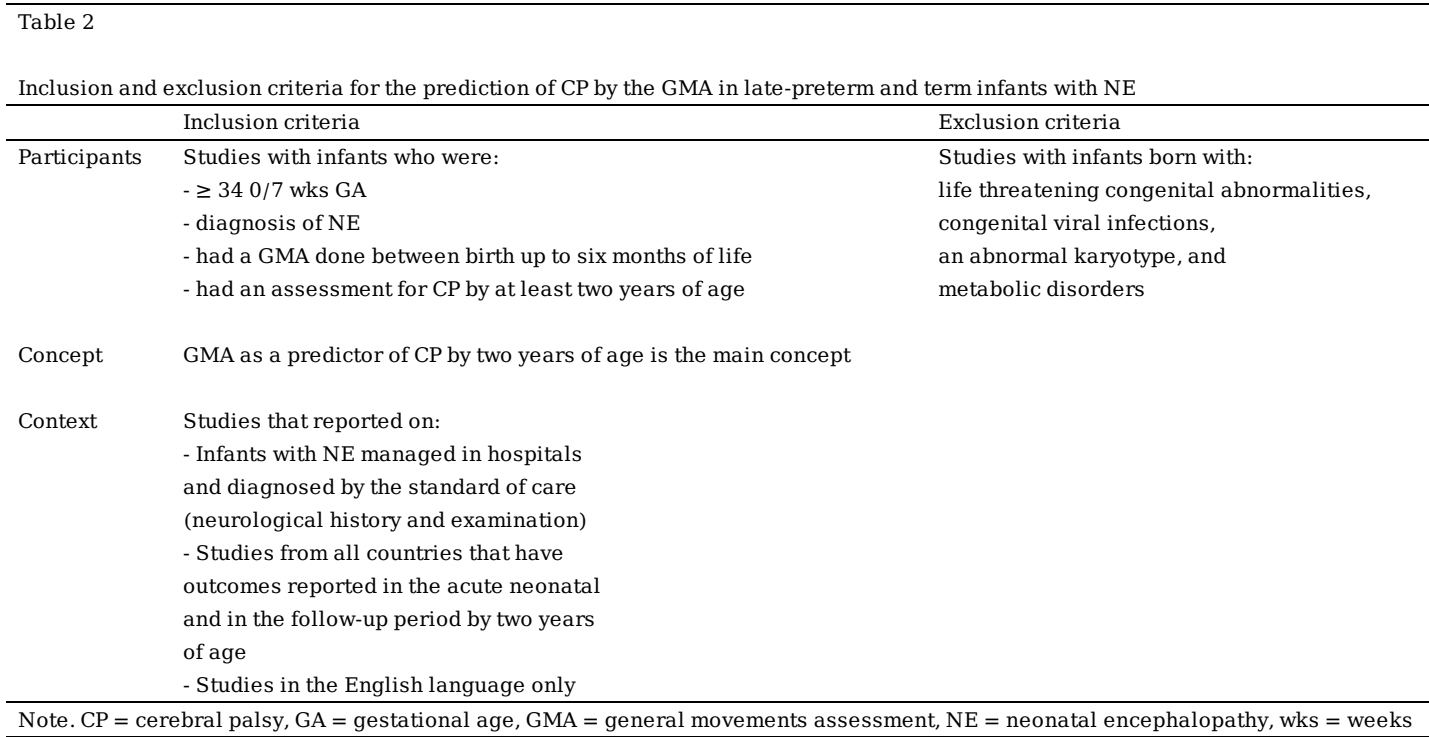

\section{Participants}

Our chosen population encompasses an age group $\geq 34$ 0/7 weeks GA as the option in this group exists for medical management for NE that significantly impacts neurological outcomes, specifically therapeutic hypothermia ${ }^{20}$. Current eligibility criteria for therapeutic hypothermia has been determined by randomized controlled trials, supporting intervention in infants $\geq 35$ weeks $\mathrm{GA}^{41}$. There are variations in practice with consideration for extension of treatment to younger gestational ages ${ }^{42}$. We therefore chose this GA to ensure we captured all the relevant literature.

Concept

The GMA is a non-invasive tool that has been shown to have predictive validity for $\mathrm{CP}^{6}$. Traditionally, CP has been diagnosed by 12 to 24 months ${ }^{11,43}$. We considered a diagnosis by two years as by this time the majority of diagnoses should be made ${ }^{6}$.

For the GMA to be used as a predictive tool for CP we considered studies with the statistical tests named in Table 2 above, as these would provide the best guidance for this clinical application ${ }^{44}$. Detailed definitions of concepts can be found in Table 3 (Additional file 1).

\section{Context}

Management affects outcome and so to potentially avoid having results that were vastly different due to non-hospital based management, we restricted our search to studies with in-hospital care in the acute period. We also considered the variability in the diagnosis of NE and so chose a baseline of at least a history and neurological examination for the diagnosis. We chose to look at all countries to be able to be as exhaustive as possible in our search.

Studies in the English language only were considered as there is no team member with adequate language skills to translate from any other language.

\section{Search strategy and databases searched}

A range of electronic databases were searched to include medicine, nursing, allied health professions, sociology, psychology, education and social work. This scoping review considered both experimental and quasi-experimental study designs including randomized controlled trials, nonrandomized controlled trials, before and after studies and interrupted time-series studies. Case reports, case series, case control and cross-sectional studies and systematic reviews that met the inclusion criteria were included. Text and opinion papers were not considered for inclusion in this scoping review as this is a highly specific and medical topic. Animal studies were not included. Studies published from at least 1970 were included. Prechtl

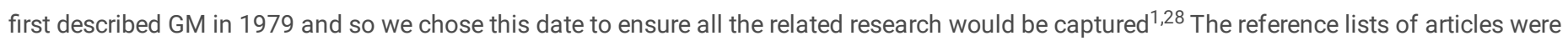
scanned and experts in the infant developmental field were consulted to identify studies relevant to our topic.

The search strategy was phased, firstly created in Ovid Medline using a combination of index terms and keywords around general movements, Prechtl, brain disease, HIE and perinatal asphyxia. An initial limited search of Ovid Medline, Embase and PsychINFO was undertaken to identify articles on the topic (See Additional file 3). There were no previous similar reviews. The text words contained in the titles and abstracts of relevant articles, and the index terms used to describe the articles from this limited search were then used to develop a more refined full search strategy in the second phase, for MEDLINE, Embase, PsychINFO, Scopus and CINAHL (Additional file 4). The search strategy, including all identified keywords and index terms, were adapted for each included information source. 


\section{Study selection}

EndNote X9 was used for citation collation. Duplicates were removed manually. Covidence was used for screening by two independent reviewers (JS and $\mathrm{ML}$ ). Disagreements were resolved through a third reviewer (RB). The results of the search were reported in a Preferred Reporting Items for Systematic Reviews and Meta-analyses extension for scoping reviews ${ }^{51}$.

Ethical approval was not required as this was a scoping review and did not contain information directly identifying patients or content requiring patient consent. We conducted our bibliographic database searches between April 30, 2019 and March 30, 2020. The reference lists of all full-text relevant studies that were identified were hand-searched for additional relevant studies. Citations were identified, duplicates removed and screened by two independent reviewers (JS, ML). Relevant studies were identified for full text review and searched for via Google Scholar, institutional journal access, e-Resources and databases sites. Any disagreements that arose between the reviewers at each stage of the study selection process was resolved through discussion. A third reviewer (RB), was the final arbitrator for any unresolved disagreements.

From the full texts, articles were selected for further review that met most of the inclusion and exclusion criteria. From these, articles were identified that fully met all the criteria. The results of the search were reported in a Preferred Reporting Items for Systematic Reviews and Meta-analyses (PRISMA-SCR) flow diagram ${ }^{52}$. Each article was independently reviewed and assessed by two of the authors (JS, ML). The data was extracted from articles using a data extraction tool developed by the reviewers. The format for the data extraction tool was modeled after that used by Kwong et al. in their 2018 review $^{27}$. This decision was taken as that review aligned well with our study in describing the predictive ability of GM for later CP, although not specifically to our population.

The distribution of the studies was determined by year of publication, as well as country of origin. These were important contextual factors as the older studies and the physical and human resources of each country may have posed limiting factors. A major consideration could have been the ability to obtain a representative portion of the population which affects the generalizability of the results. The study characteristics included information such as gender, GA, birth weight, numbers of term and late-preterm neonates in the sample as well as the overall sample size, number of neonates diagnosed with NE and the number of cases of $\mathrm{CP}$.

\section{Results}

Following the searches, 883 citations were identified. The results of the search were reported here in a flow diagram (Figure 1), adapted from the PRISMA-ScR ${ }^{52}$ structure.

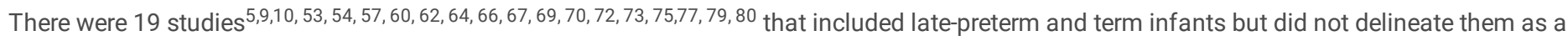
specific group as it relates to their diagnosis of NE and their CP outcomes and when using GMA as a predictive tool. Table 4 (Additional file 4 ) presents the summary of the characteristics of the excluded studies. There was a wide variety in their key characteristics. We summarized these characteristics here. These studies had a wide date range from 1997 to 2019 . They were mainly prospective studies (14 of the 19) and the majority used clinical assessments only to identify infants at high risk (10 of the 19). With regards to the assessment tools used, of the 19 studies, 18 used the GMA by Prechtl. For the age at which CP was diagnosed, 12 of the excluded studies used the same criteria as we did in this study, that is, CP diagnosis by at least 2 years. For the method of CP diagnosis, a variety of standardized assessments were used, with the most frequent being by Amiel-Tison and Grenier ${ }^{58}$.

Eight studies either used non-standardized methods or did not clearly state their method.

Table 5 (Additional file 4) presents the summary of the key findings of these excluded studies and reasons for their exclusion. These findings showed that in high-risk infants, including those with NE, GMA is a strong predictor of $\mathrm{CP}^{53}$, especially when used in the fidgety period period ${ }^{10,54,67,69,75,79}$. In 1997 Prechtl et al. ${ }^{5}$ demonstrated that movement quality was important. Abnormal quality and absent fidgety movements, in a mixed group of preterm and term infants, predicted neurological abnormalities with a sensitivity of $96 \%$. The majority of these were diagnosed as CP. We see in our results, that over time this result has been repeatedly duplicated showing that $\mathrm{CS}^{60}$ and absent fidgety ${ }^{70} \mathrm{GM}$ are highly predictive of $\mathrm{CP}$. The trajectory of the GMA is more important as a predictor of $\mathrm{CP}^{54}$.

The GMA is more sensitive than the traditional neurological examination $55,60,64$ and the sensitivity increases with combined use of other modalities such as electroencephalogram (EEG) ${ }^{64}$, neuroimaging ${ }^{77}$, Hammersmith Infant Neurological Examination (HINE) and neuroimaging ${ }^{70}$.

For these excluded studies, sensitivity values were as high as $100 \% 53,54,60,66,69$ and specificity similar close to 53,70 or at $100 \%$. We contacted the authors of the study closest to our inclusion criteria, Solemani et al ${ }^{75}$, as they delineated their populations by NE and by GA but their outcome was reported as "neurodevelopmental outcomes" and not CP. They reported to us that they did not specifically report CP and so could not be included for us. PPV and NPV was reported for eight of the excluded studies $5,64,46,67,70,73,75,77$ with some studies reporting PPV as high as $98 \%$ when used in combination with HINE and neuroimaging ${ }^{70}$ and NPV as high as $100 \%{ }^{66}$. Themes for the limitations identified by the authors can be summarized as limited external validity due to small population size, ${ }^{60,62,70,79,80}$ selection bias related to recruitment from high-risk populations ${ }^{5,9,70}$, and practice 
variation between sites $53,66,69$. The most common reasons for exclusion of these studies were failure to delineate their participants for the diagnosis of NE, most quoting their participants as high-risk infants, or not delineating their GA into the groups relevant to our questions (late-preterm and term).

Only two articles therefore, one by Ferrari et al. ${ }^{81}$ and the other by Prechtl et al. ${ }^{82}$, were identified as meeting selection criteria and were included in the final review. The results of the search were reported here in a flow diagram (Figure 1) ${ }^{52}$. The final two studies included were case series ${ }^{81,82}$ from Italy. The total number of participants were only 60 term neonates (34 and 26 participants respectively); neither included late-preterm neonates. NE was reported as a single group by Ferrari et al. ${ }^{81}$ but divided into mild-moderate and severe by Prechtl et al. ${ }^{82}$. The high-risk groups in both studies were identified by history only. The GMA used by both studies was Prechtl. Table 6 (Additional file 4) presents the characteristics of these two studies. Both were published more than five years ago and reported on sensitivity, specificity, positive predictive value (PPV) and negative predictive value (NPV).

A variety of standardized tools were used for CP diagnosis between the two studies. Table 7 (Additional file 4) details the key findings and the outcomes evaluated, with the limitations identified by the authors. In the more recent study, Ferrari et al. ${ }^{81}$ reported that the presence of any CS movements between term and four to five months post-term had a sensitivity of $100 \%$, specificity of $68.7 \%$, with a PPV $100 \%$ and a NPV of $78.3 \%$ for predicting CP. In the older study by Prechtl et al. ${ }^{82}$, the predictive ability in terms of the timing of the GMA was determined, that is, if done early, in the first two weeks of life versus late assessments between 15-22 weeks of life. Their findings were: sensitivity $100 \%$, specificity $46.2 \%$, with PPV $65.0 \%$ and NPV $100 \%$ for the early assessments, compared to late assessments with $84.6 \%$ across the board for sensitivity, specificity, PPV and NPV. Neither of the studies included infants receiving therapeutic hypothermia for NE which was not yet the standard of care. Ferrari et al. ${ }^{81}$ identified selection bias as a limitation, where mild HIE as a contributor to NE may have been underrepresented due to these infants not being referred for evaluation. Prechtl et al. ${ }^{82}$ did not state their limitations.

\section{Risk of Bias}

Even though this was a scoping review and did not require the critical appraisal of the two included articles, the critical appraisal tool for $\mathrm{JBI}^{83}$ helped to identify differences and similarities between these two case studies. These main points are summarized here and details are presented in Table 8 (Additional file 5).

The quality of evidence derived from a review is largely dependent on the quality of the studies included. Neither study scored $100 \%$ on all ten questions. The two studies scored $100 \%$ for six of the ten questions on the checklist. These questions assess the two included studies as being moderate quality case series as there were limitations. They had good scores for using valid methods for identification of the condition for all participants, having clear reporting of the demographics of the participants in the study, as well as, having clear clinical information of the participants. The outcomes of the cases were clearly reported for both studies. They also had clear reporting of the presenting sites demographic information and used appropriate statistical analysis.

According to the JBI method, for the study participants, the authors should provide clear and exclusion criteria. These inclusion and exclusion criteria should be specified with sufficient detail and all the necessary information critical to the study. While Ferrari et al. ${ }^{81}$ did fulfil this criteria, of note, Prechtl et al. ${ }^{82}$ did not state their exclusion criteria and so this may limit the generalizability of the results. For good quality case series, the study should clearly describe the method of measurement of the condition. This should be done in a standard (i.e. same way for all patients) and reliable (i.e. repeatable and reproducible results) way. The clinical condition for our study is NE. Both studies listed a number of criteria for possible inclusion for NE but did not state the number or combination of these criteria required for the diagnosis and so scored $0.0 \%$ for this question. They did use a standard, albeit different, method for NE severity, with Ferrari et al. ${ }^{81}$ use the Sarnat staging ${ }^{22}$ while Prechtl et al. ${ }^{82}$ used the Levene method ${ }^{84}$. With regards to consecutive inclusion, studies that indicate a consecutive inclusion are more reliable than those that do not. Neither of our included studies stated clearly if they did consecutive inclusion of every neonate meeting the inclusion criteria, at their institutions, during the identified periods. Thus they both scored $0.0 \%$ for this. Along a similar vein, the completeness of a case series contributes to its reliability. Studies that indicate a complete inclusion are more reliable than those that do not. Neither Ferrari et al. ${ }^{81}$ nor Prechtl et al. ${ }^{82}$ clearly stated that they included all the patients in their studies and scored $0.0 \%$ for this question.

The biases include selection, information and sampling variation. Selection bias is typical of case series as it is a choice of a series of patients with a particular illness (NE), and a suspected linked outcome $(\mathrm{CP})^{85}$. Selection bias limits the generalizability of results. Information bias is less in retrospectively collected data as it is determined by what is already documented in the medical chart. These two studies both were prospectively collected data making them susceptible to information bias. With regards to sampling variation, the precise determination of the rate of a disease, other than by chance, requires a large sample size. Both studies can be described as employing small sample sizes, Ferrari et al. ${ }^{81}$ had 34 cases and Prechtl et al. ${ }^{82}$ had 26 cases with a follow up period of over three to four years. Sample size may have been limited by the collection method as neither study stated if they were inclusive of every neonate meeting the inclusion criteria, at their institutions, during the identified periods.

\section{Discussion}

The scoping review methodology provided valuable insight to the current limited state of knowledge on the use of the GMA in the term neonate diagnosed with NE to predict CP by the age of 2 years. In fact, in the late preterm infant with NE there was no evidence that met our inclusion criteria. 
Furthermore, the evidence was derived from case studies which does not constitute a level of evidence on which we can base definite recommendations. Our scoping review results highlights the need for more specific, higher quality research in this area.

From the review we were able to glean some important insights for the use of the GMA in our population. In both studies the presence of the CS movement pattern of the GMA does correlate with the prediction of CP by two years of age. Prechtl et al. ${ }^{82}$ noted that NE has an effect on spontaneous movements in term neonates, be it transient or persistent. Early assessments may be unable to differentiate between abnormal spontaneous movements that may be transient from those that will persist and eventually be associated with CP. Early assessments do not give as good predictive values as later assessments therefore the trajectory of the GMA may be a more significant indicator of outcomes than a solitary assessment ${ }^{54,82}$.

\section{Limitations of the included studies}

Our findings support the role of the GMA as a good tool for prediction of CP for those infants born at term with NE. There are however limitations to consider including: both publications were case series, the variability in the NE definitions, the date of the publications identified and neither study contained neonates treated with the now standard of care, therapeutic hypothermia. Another important limitation is the low number of studies meeting our inclusion criteria.

Firstly, internal validity is likely to be low, as occurs in case series, since there are no comparator groups exposed to a similar array of variables. External validity would similarly be limited. Since this scoping review only represents Level IV evidence ${ }^{86}$ it reveals the need for future research in this area since it suggests that neonates with $\mathrm{NE}$, at least those at term may benefit from follow-up assessments with the GMA to help earlier identification of CP.

Secondly, in terms of the definition of NE, for the study by Ferrari et al. ${ }^{81}$ there were some differences in the way NE was defined. In general, the standard accepted criteria that defines NE was used, but they stated that study participants had different combinations of the NE criteria. Evidence shows that the etiology 23,27 of encephalopathy as well as its severity ${ }^{23}$ may influence outcomes. Although the severity of NE (that is, mild, moderate or severe reflected by the Sarnat stage) was assessed in the study, no further differentiation of severity as it related to the predictive ability for CP was done. This may have been due to the small sample size of the study $(n=34)$ and the inevitable decreased power that would have resulted from subdivisions. Prechtl ${ }^{82}$ also subdivided the NE diagnosis into mild to moderate $(n=13)$ and severe $(n=13)$ NE. Similar to Ferrari ${ }^{81}$, outcomes were not reported according to these NE subdivisions.

Thirdly, in terms of the timing of the publications, both were more than five years old. Management has changed over time and updated data in this evolving area would be beneficial. It is however interesting that the older study by Prechtl et al. ${ }^{82}$ in 1993 supports the same later findings of the Ferrari et al. ${ }^{81}$ study in 2011 with respect to the predictive ability of the GMA. This lends support to the reliable role of the GMA in the identification of those children born at term with NE who are at risk for CP.

Fourthly, neither of the studies seemed to have been done in neonates treated with therapeutic hypothermia, which is the current standard of care ${ }^{18,19}$. We are therefore uncertain if therapeutic hypothermia changes the quality of the GM and if it does change, how long might this persist. Information like this is important to inform the timing of the early GMA-post therapeutic hypothermia intervention. Similar consideration had to be done for identifying the optimal window for cranial MRI in neonates treated with therapeutic hypothermia ${ }^{87}$. This lends credence to the gap in research in this area of NE and its association with CP.

\section{Strengths and Limitations of this review}

The strength of our review primarily lies in the Scoping review methodology that we chose. This method was advantageous as it facilitated an exhaustive search of the literature to define the current extent of knowledge and so allowed the research gaps to be identified.

We appreciated that there were several limitations. Firstly, we excluded studies that were not in English. This may be significant as there were only two studies identified in the review that met the established inclusion criteria. Therefore with this limited number any additional studies may have impacted our results. Secondly, the ages of the studies are of concern. The study that was published in 2011 by Ferrari ${ }^{81}$, recruited participants between 2003 and 2006. The cohort of the Prechtl study was recruited between 1985 and 1989. Medical management has evolved since then to include strategies such as therapeutic hypothermia ${ }^{18,19}$. The impact of this on our results is unknown. Lastly, we recognize that using a cut off of CP diagnosis by two years of age constitutes a limitation as milder forms of CP may not be identified by this age.

\section{Suggestions for further research}

This review elucidates multiple potential areas for research.

\section{Quantitative research:}

Meta-analysis - A meta-analysis of the data was not possible due to the minimal number of studies available. As more data becomes available more accurate suggestions, for the use of the GMA in our population, can be made. 
Prospective study - To provide higher quality evidence, a prospective study looking at the use of the GMA with the MOS in our population of term and late-preterm infants diagnosed with NE is needed. Medical management has changed since the era of the cohorts included in this review. The link of the GMA with respect to NE severity, etiology and contemporary management would be of benefit.

Predictive ability of GMA in CP severity in our population - Determination of the predictive ability of the GMA, including the MOS, for the degree of functionality in CP, such as that determined by the Gross Motor Function Classification System (GMFCS) ${ }^{63}$ scoring system would be beneficial for implementation of early intervention strategies.

Optimal timing of an early assessment - Since the trajectory of the GM may provide significant clues to neurodevelopmental outcomes more research is needed in this area. Transient effects on the GM may result from medical management such as therapeutic hypothermia and medications including sedatives and anticonvulsants. Optimal timing of the first assessment in this population requires further elucidation.

Qualitative research:

Parental counseling and anticipatory intervention - Parental perspectives on the use of the GMA as a predictor of neurodevelopmental outcomes in our population would be desirable for future research. This would influence counseling by the medical teams with regards to reassurance or the need for early intervention and extent of neurodevelopmental follow-up.

\section{Conclusion}

The finding of CS GM is a predictor for the diagnosis of CP by two years of age in the term population with NE. In term infants with encephalopathy the predictive ability of the GMA is not as reliable when performed early versus later (at 15-22 weeks of age). Additionally, there are no existing studies specific to the application of the GMA in late-preterm infants with NE.

The deficit of high quality research limits the applicability and so the GMA should not be used in isolation when assessing these populations. The evidence for this is limited by few studies and a lack of high quality research. The evidence is lacking for the utilization of the GMA in these populations treated with therapeutic hypothermia. Furthermore, of possibly greater potential applicability is the inclusion of the MOS as a predictor of $\mathrm{CP}^{7,8}$ in term and late preterm infants with NE when treated with therapeutic hypothermia.

\section{List Of Abbreviations}

BW, birth weight; $\mathrm{Cl}$, confidence interval; CP, cerebral palsy; CS, cramped synchronized; EEG, electroencephalogram; ELBW, extremely low birth weight; FM, fidgety movements; GA, gestational age; GM, general movements; GMA, general movements assessment; GMFCS, Gross Motor Function Classification System; HIE, hypoxic ischemic encephalopathy; HINE, Hammersmith Infant Neurological Examination; JBI, Joanna Briggs Institute; LR, likelihood ratio; LBW, low birth weight; MOS Motor Optimality Score; MRI, magnetic resonance imaging; NAPI, Neurobehavioral Assessment of the Preterm Infant, NBW, normal birth weight; NE, Neonatal encephalopathy; NPV, negative predictive value; n.s., not stated; PCC, participant, concept, context; PMA, postmenstrual age; PR, poor repertoire; PPV, positive predictive value; PRISMA-ScR, Preferred Reporting Items for Systematic Reviews and Meta-analyses extension for scoping review; TIMP, Test of infant motor performance, SD, standard deviation; US, ultrasound; VLBW, very low birth weight; wks, weeks.

\section{Declarations}

\section{Ethics approval and consent to participate}

Ethical approval was not required as this is a scoping review of the literature and did not contain information directly identifying patients or content requiring patient consent.

\section{Consent for publication}

Not applicable

\section{Availability of data and materials}

Data sharing is not applicable to this article as no datasets were generated or analysed during the current study. Materials during the current study are available from the corresponding author on reasonable request.

\section{Competing interests}

The authors declare that they have no competing interests.

Funding 
There is no funding required for this review.

\section{Authors' contributions}

First author: Judy Seesahai

Contributions: Substantial contributions to research design, acquisition, analysis and interpretation of data as well as drafting the paper.

Second author: Thomas Rotter

Contributions: Substantial contributions to research design and reviewing of the paper.

Second author: Maureen Luther

Contributions: Contribution to acquisition, analysis and interpretation of data as well as involved in revisions to the paper.

Patricia Maddalena

Contributions: Contribution to acquisition, analysis and interpretation of data as well as involved in revisions to the paper.

Paige Terrien Church

Contributions: Substantial contributions to research design, analysis and interpretation of data as well as drafting the paper.

Elizabeth Asztalos

Contributions: Substantial contributions to research design, acquisition, analysis and interpretation of data as well as drafting the paper.

Principal Investigator: Rudaina Banihani

Contributions: Substantial contributions to research design, acquisition, analysis and interpretation of data as well as drafting the paper.

\section{Acknowledgements}

This review contributed to a Master in Healthcare Quality degree for JS. The authors would also like to acknowledge the librarians that assisted with this research project, namely from the Sunnybrook R. lan MacDonald Library, Henry Lam and Reena Besa, as well as the librarians Paola Durando and Sandra McKeown of the Bracken Health Sciences Library, Queen's University.

\section{References}

1. Prechtl HFR, Fargel JW, Weinmann HM, Bakker HH. Postures, motility and respiration of low-risk preterm infants. Dev Med Child Neurol. 1979;21:3-27. Available from: http://resolver.scholarsportal.info.myaccess.library.utoronto.ca/resolve/00121622/v21i0001/3_pmarolpi.xml DOI: https://doi-org.myaccess.library.utoronto.ca/10.1111/j.1469-8749.1979.tb01577.x

2. de Vries JIP, Visser GHA, Prechtl HFR. The emergence of fetal behaviour. I. Qualitative aspects. Early Hum Dev [Internet]. 1982 Dec 30;7(4):30122. Available from: http://resolver.scholarsportal.info.myaccess.library.utoronto.ca/resolve/03783782/v07i0004/301_teofbiqa.xml DOI https://doi-org.myaccess.library.utoronto.ca/10.1016/0378-3782(82)90033-0

3. Einspieler C, Prechtl HFR, Bos AF, Ferrari F, Cioni G. Prechtl's method on the qualitative assessment of general movements in preterm, term and young infants. $1^{\text {st }}$ London, UK: MacKeith Press;2004.

4. Bosanquet M, Copeland L, Ware R, Boyd R. A systematic review of tests to predict cerebral palsy in young children. Dev Med Child Neurol. 2013;55:418-26.

5. Prechtl HF, Einspieler C, Cioni G, Bos AF, Ferrari F, Sontheimer D. An early marker for neurological deficits after perinatal brain lesions. Lancet [Internet]. 1997 May 10;349(9062):1361-3. Available from:

http://resolver.scholarsportal.info.myaccess.library.utoronto.ca/resolve/01406736/v349i9062/1361_aemfndapbl.xml DOI https://doiorg.myaccess.library.utoronto.ca/10.1016/S0140-6736(96)10182-3

6. Hadders-Algra M. General movements: a window for early identification of children at high risk for developmental disorders. J Pediatr. 2004 May 11;145(2 Supplement):S12-8.

7. Bruggink, JL, Cioni, G, Einspieler, C, Maathuis, CG, Pascale, R. and Bos, AF. Early motor repertoire is related to level of self- mobility in children with cerebral palsy at school age. Dev Med Child Neurol. 2009;51:878-85. doi:10.1111/j.1469-8749.2009.03294.x 
8. Einspieler C, Marschik PB, Bos AF, Ferrari F, Cioni G, Prechtl HFR. Early markers for cerebral palsy: insights from the assessment of general movements. Future Neurol. 2012 Nov;7(6):709-717. DOI https://doi.org/10.2217/fnl.12.60

9. Einspieler C, Bos A, Krieber-Tomantschger M, Alvarado E, Barbosa V, Bertoncelli N, et al. Cerebral palsy: early markers of clinical phenotype and functional outcome. J. Clin. Med. 2019, 8(10),1616. Available from:https://www.mdpi.com/2077-0383/8/10/1616 DOI https://doi.org/10.3390/jcm8101616

10. Yang H, Einspieler C, Shi W, Marschik PB, Wang Y, Cao Y. Cerebral palsy in children: movements and postures during early infancy, dependent on preterm vs. full term birth. Early Hum Dev. 2012.88(10):837-43. Available from: https://proxy.queensu.ca/login?url=http://ovidsp.ovid.com? $\mathrm{T}=\mathrm{JS} \& C S C=Y \& N E W S=N \& P A G E=$ fulltext\&D=med8\&AN=22795821 https://www.sciencedirect.com/science/article/abs/pii/S0378378212001533? via\%3Dihub DOI: https://dx.doi.org/10.1016/j.earlhumdev.2012.06.004

11. Rosenbaum P, Paneth N, Leviton A, Goldstein M, Bax M, Damiano D, et al. A report: the definition and classification of cerebral palsy April 2006. Dev Med Child Neurol Suppl. 2007;109:8-14.

12. Nelson KB. The epidemiology of cerebral palsy in term infants. Ment Retard Dev Disabil Res Rev [Internet]. 2002;8(3):146-50. Available from: http://resolver.scholarsportal.info.myaccess.library.utoronto.ca/resolve/10804013/v08i0003/146_teocpiti.xml DOI https://doiorg.myaccess.library.utoronto.ca/10.1002/mrdd.10037

13. Watson L, Blair E, Stanley F. Report of the Western Australian cerebral palsy register - to birth year 1999. Perth. 2006. [Accessed: Dec 13, 2020]. Available from: https://www.kemh.health.wa.gov.au/ /media/Files/Hospitals/WNHS/Our\%20Services/Statewide\%20Services/WARDA/Reports/2006_Report_of_the_WA_Cerebral_Palsy_Register.pdf

14. Chalak L, Ferriero DM, Gressens PA, Molloy E, Bearer C. A 20 years conundrum of neonatal encephalopathy and hypoxic ischemic encephalopathy: are we closer to a consensus guideline? Pediatr Res2019;86:548-549. DOI https://doi.org/10.1038/s41390-019-0547-9

15. Report of the American College of Obstetricians and Gynecologists' Task Force on Neonatal Encephalopathy. Executive summary: Neonatal encephalopathy and neurologic outcome, 2nd ed. Obstet Gynecol. 2014 Apr;123(4):896-901. doi: 10.1097/01.A0G.0000445580.65983.d2 PMID: 24785633

16. Volpe JJ. Neonatal encephalopathy: An inadequate term for hypoxic-ischemic encephalopathy. Ann Neurol [Internet]. 2012 Aug 1;72(2):156-66. Available from: http://resolver.scholarsportal.info.myaccess.library.utoronto.ca/resolve/03645134/v72i0002/156_neaitfhe.xml DOI https://doiorg.myaccess.library.utoronto.ca/10.1002/ana.23647

17. Ellenberg JH, Nelson KB. The association of cerebral palsy with birth asphyxia: a definitional quagmire. Dev Med Child Neurol [Internet]. 2013 Mar 1;55(3):210-6. Available from:

http://resolver.scholarsportal.info.myaccess.library.utoronto.ca/resolve/00121622/v55i0003/210_taocpwbaadq.xml

18. Glass HC. Hypoxic-Ischemic Encephalopathy and Other Neonatal Encephalopathies. Child Neurol. Continuum (Minneapolis, Minn.). 2018 Feb;24(1):57-71. DOI: 10.1212/con.0000000000000557

19. American Academy of Pediatrics, Committee on Fetus and Newborn. Hypothermia and neonatal encephalopathy. Pediatrics. 2014 Jun;133(6):1146-50.

20. Tagin MA, Woolcott CG, Vincer MJ, Whyte RK, Stinson DA. Hypothermia for neonatal hypoxic ischemic encephalopathy: an updated systematic review and meta-analysis. Arch Pediatr Adolesc Med 2012; 166:(06): 558-566

21. Staub K, Baardsnes J, Hébert N, Hébert M, Newell S, Pearce R. Our child is not just a gestational age. A first- hand account of what parents want and need to know before premature birth. Acta Paediatr. 2014;103(10):1035-38

22. Sarnat H, Sarnat M. Neonatal encephalopathy following fetal distress. Arch Neurol.1976.33:695-705.

23. Miller SP, Latal B, Clark H, Barnwell A, Glidden D, Barkovich AJ, et al. Clinical signs predict 30-month neurodevelopmental outcome after neonatal encephalopathy. Am J Obstet Gynecol. 2004.190(1):93-99. DOI: https://doi.org/10.1016/S0002-9378(03)00908-6

24. Finer NN, Robertson CM, Richards RT, Pinnell LE, Peters KL. Hypoxic-ischemic encephalopathy in term neonates: perinatal factors and outcome. J Pediatr. 1981 Jan;98(1):112-7. DOI: 10.1016/s0022-3476(81)80555-0

25. Campbell EE, Gilliland J, Dworatzek PDN, De Vrijer B, Penava D, Seabrook JA. Socioeconomic status and adverse birth outcomes: a populationbased Canadian sample. J Biosoc Sci. Cambridge University Press; 2018;50(1):102-13.

26. Banihani R, Church PT, Luther M, Maddalena P, Asztalos E. Neonatal Encephalopathy. In: Needelman H JB, editor. Follow-Up for NICU Graduates. 2018;155-78. 
27. Kwong AKL, Fitzgerald TL, Doyle LW, Cheong JL, Spittle AJ. Predictive validity of spontaneous early infant movement for later cerebral palsy: a systematic review. Dev Med Child Neurol. 2018 Feb 22;60(5):480-489.

28. Novak I, Morgan C, Adde L, et al. Early, accurate diagnosis and early intervention in cerebral palsy: advances in diagnosis and treatment. JAMA Pediatr. 2017;171(9):897-907. doi:10.1001/jamapediatrics.2017.1689

29. Noble Y \& Boyd R. Neonatal assessments for the preterm infant up to 4 months corrected age: a systematic review. Dev Med Child Neurol. 2012 Nov, 54:129-39.

30. Zuk L. Fetal and infant spontaneous general movements as predictors of developmental disabilities. Dev Disabil Res Rev.2011;17:93-101. Available from: https://proxy.queensu.ca/login?url=http://ovidsp.ovid.com?T=JS\&CSC=Y\&NEWS=N\&PAGE=flltext\&D=med7\&AN=23362029 https://onlinelibrary.wiley.com/doi/abs/10.1002/ddrr.1104https://dx.doi.org/10.1002/ddrr.1104

31. Darsaklis V, Snider LM, Majnemer A, Mazer B. Predictive validity of Prechtl's method on the qualitative assessment of general movements: a systematic review of the evidence. Dev Med Child Neurol. 2011 Jun 17;53(10):896-906.

32. Burger M, Louw QA. The predictive validity of general movements - a systematic review. Eur J Paediatr Neurol. 2009;13(5):408-20.

33. Spittle AJ, Doyle LW, Boyd RN. A systematic review of the clinimetric properties of neuromotor assessments for preterm infants during the first year of life. Dev Med Child Neurol. 2008 Apr 8;50(4):254-66.

34. Hadders-Algra M. Evaluation of motor function in young infants by means of the assessment of general movements: a review. Pediatr Phys Ther. 2001 Apr 1;13(1):27-36.

35. Santos RS., Araújo APQC., Porto MAS. Early diagnosis of abnormal development of preterm newborns: assessment instruments. J. Pediatr. (Rio J.) [Internet]. 2008 Aug [cited 2019 Aug 07];84(4):289-299. Available from: http://www.scielo.br.proxy.queensu.ca/scielo.php? script=sci_arttext\&pid=S0021- 75572008000400003\&lng=en. http://dx.doi.org.proxy.queensu.ca/10.1590/S0021- 75572008000400003.

36. Raghuram K, Orlandi S, Church P, Chau T, Uleryk E, Pechlivanoglou P, et al. Can an automated general movements assessment be used to predict motor impairment in high-risk infants? A systematic review and meta-analysis of diagnostic accuracy. PROSPERO International prospective register of systematic reviews. 2018 Apr 16; Available from: http://www.crd.york.ac.uk/PROSPERO/display_record.php?ID=CRD42018087892.

37. Valencia A. Discriminative and predictive validity of the general movements assessment: a systematic review. PROSPERO International prospective register of systematic reviews. 2018 Feb 14; Available from: http://www.crd.york.ac.uk/PROSPERO/display_record.php? ID=CRD42018088724.

38. Kwong AKL, Fitzgerald TL, Spittle AJ, Cheong JL, Doyle LW, Einspieler C. A systematic review of the predictive validity of observational early infant motor assessments for subsequent cerebral palsy. PROSPERO International prospective register of systematic reviews. 2016; Available from: http://www.crd.york.ac.uk/PROSPERO/display_record.php?ID=CRD42016042551.

39. Seesahai J, Luther M, Rhoden CC, Church PT, Asztalos E, Banihani R. The general movements assessment in term and late-preterm infants diagnosed with neonatal encephalopathy, as a predictive tool of cerebral palsy by 2 years of age: a scoping review protocol. Syst Rev. 2020 9:154. Available from: https://doi.org/10.1186/s13643-020-01358-xDOI https://doi-org.myaccess.library.utoronto.ca/10.1186/s13643-02001358-x

40. The Joanna Briggs Institute. The System for the Unified Management, Assessment and Review of Information (SUMARI) [Internet]. 2017 [cited 2019]. Available from: https://www.jbisumari.org/

41. Hypothermia and Neonatal Encephalopathy. Committee on fetus and newborn. Pediatrics. Jun 2014, 133(6)1146-1150; Available from: https://pediatrics.aappublications.org/content/133/6/1146 DOI: 10.1542/peds.2014-0899.

42. Burnsed J, Zanelli SA. Neonatal therapeutic hypothermia outside of standard guidelines: a survey of U.S. neonatologists. Acta Paediatr [Internet]. 2017 Nov 1;106(11):1772-9. doi:10.1542/peds.2014-0899 Available from: http://resolver.scholarsportal.info.myaccess.library.utoronto.ca/resolve/08035253/v106i0011/1772_nthoosgasoun.xml

43. Report of the Australian Cerebral Palsy Register, Birth Years 1993-2009, September 2016. Available from: https://www.cpregister.com/pubs/pdf/ACPR-Report_Web_2016.pdf.

44. Trevethan R. Sensitivity, specificity, and predictive values: foundations, pliabilities, and pitfalls in research and practice. Front Public Health. 2017;5:307. DOI: https://doi.org/10.3389/fpubh.2017.00307

45. Raju TN, Higgins RD, Stark AR, Leveno KJ. Optimizing care and outcome for late-preterm (near-term) infants: a summary of the workshop sponsored by the National Institute of Child Health and Human Development. Pediatrics. 2006 Sep;118(3):1207-14. doi: 10.1542/peds.2006-

Page $11 / 15$ 
0018. PMID: 16951017

46. Engle WA, Tomashek KM, Wallman C. Late-preterm infants: a population at risk. Pediatrics 2007 Dec;120(6):1390-1401. DOI: 10.1542/peds.20072952

47. Committee opinion no. 579: definition of term pregnancy. Obstet Gynecol. 2013;122(5):1139-1140. doi:10.1097/01.A0G.0000437385.88715.4a

48. Einspieler C, Prechtl HFR. Prechtl's assessment of general movements: a diagnostic tool for the functional assessment of the young nervous system. Ment Retard Dev Disabil Res Rev. 2005;11(1):61-6.

49. Altman DG, Bland JM. Diagnostic tests 1: Sensitivity and specificity. BMJ. 1994 Jun 11;308(6943):1552. doi: 10.1136/bmj.308.6943.1552. PMID: 8019315; PMCID: PMC2540489.

50. Altman DG, Bland JM. Diagnostic tests 2: Predictive values. BMJ (Clinical research ed). 1994;309(6947):102. https://doi.org/10.1136/bmj.309.6947.102

51. Tricco AC, Lillie E, Zarin W, O'Brien KK, Colquhoun H, Levac D, et al. PRISMA extension for scoping reviews (PRISMAScR): checklist and explanation. Ann Intern Med. 2018;169:467-473. doi: 10.7326/M18-0850.

52. Moher D, Liberati A, Tetzlaff J, Altman DG. Preferred reporting items for systematic reviews and meta-analyses: the PRISMA statement. [Internet]. 2009 [cited 2019]. Available from: http://prisma-statement.org/PRISMAStatement/FlowDiagram.aspx

53. Adde L, Rygg M, Lossius K, Oberg GK, Stoen R. General movement assessment: predicting cerebral palsy in clinical practise. Early Hum Dev. 2007 Jan 83(1):13-8. DOI:https://doi.org/10.1016/j.earlhumdev.2006.03.005

54. Brogna C, Romeo DM, Cervesi C, Scrofani L, Romeo MG, Mercuri E. et al. Prognostic value of the qualitative assessments of general movements in late-preterm infants. Early Hum Dev. 2013.89:1063-66. Available from https://www.sciencedirect.com/science/article/abs/pii/S0378378213001977?via\%3DihubDOI: https://dx.doi.org/10.1016/j.earlhumdev.2013.08.008

55. Touwen BCL. Neurological development in infancy. London: MacKeith Press. 1976.

56. Bayley N. Bayley scales of infant development. 2nd ed. San Antonio, TX: Psychological Corp; 1993.

57. Cioni G, Prechtl HFR, Ferrari F, Paolicelli PB, Einspieler C, Roversi MF. Which better predicts later outcome in full-term infants: quality of general movements or neurological examination? Early Hum Dev. 1997;50:71-85. Available from:

https://www.sciencedirect.com/science/article/abs/pii/S0378378297000947?via\%3Dihub

58. Amiel-Tison C, Grenier A. Neurological assessment during the first year of life. Oxford, UK: Oxford University Press. 1986.

59. Griffiths R.: The abilities of babies: a study in mental measurement. University London Press, London. 1954.

60. Dimitrijevic L, Bjelakovic B, Colovic H, Mikov A, Zivkovic V, Kocic M. Assessment of general movements and heart rate variability in prediction of neurodevelopmental outcome in preterm infants. Early Hum Dev. 2016.99:7-12. Available from http://www.elsevier.com/locate/earlhumdevhttps://www.sciencedirect.com/science/article/abs/pii/S0378378216301050?via\%3Dihub. DOI: http://dx.doi.org/10.1016/j.earlhumdev.2016.05.014.

61. Surveillance of Cerebral Palsy in Europe (SCPE). Prevalence and characteristics of children with cerebral palsy in Europe. Dev Med Child Neurol. 2002 Sep;44(9):633-40.

62. Einspieler C, Yang H, Bartl-Pokorny KD, Chi X, Zang FF, Marschik PB. Are sporadic fidgety movements as clinically relevant as is their absence? Early Hum Dev. 2015.91.4: 247-52 Available from https://www.sciencedirect.com/science/article/abs/pii/S0378378215000377? via\%3Dihubhttps://www.ncbi.nlm.nih.gov/pmc/articles/PMC5951271/pdf/emss-77584.pdf DOI: https://dx.doi.org/10.1016/j.earlhumdev.2015.02.003.

63. Palisano RJ, Rosenbaum PL, Walter S, Russell DJ, Wood EP, Galuppi BE. Development and reliability of a system to classify gross motor function in children with cerebral palsy. Dev Med Child Neurol. 1997; 39:214-23. [PubMed: 9183258]

64. Feng J, Ruan Y, Cao Q, Chen Y, Liang X. General movements and electroencephalogram as a predictive tool of high-risk neonatal neurodevelopmental outcome. Biomed Res (India). 2017;28(18):7810-14. Available from:

http://www.biomedres.info/biomedicalresearch/general-movements-and-electroencephalogram-as-a-predictive-tool-of-highriskneonatalneurodevelopmental-outcome.pdf 
65. Gesell Institute of human development. Gesell Developmental Schedule. 1979. Available from:

https://web.archive.org/web/20160304041139/http://www.gesellinstitute.org.php53-10.dfw1-2.websitetestlink.com/wp-

content/uploads/2013/09/GesellSchedules.pdf

66. Guzzetta A, Belmonti V, Battini, R. Boldrini A, Bruna Paolicelli P, Cioni G. Does the assessment of general movements without video observation reliably predict neurological outcome? Eur J Paediatr Neurol. 2007;111(6):362-67. Available from:https://www.ejpn-journal.com/article/S10903798(07)00053-0/fulltext DOI: http://dx.doi.org/10.1016/j.ejpn.2007.03.003

67. Hadders-Algra M, Klip-van den Nieuwendijk AWJ, Martijn A, van Eykern LA. Assessment of general movements: towards a better understanding of a sensitive method to evaluate brain function in young infants. Dev Med Child Neur. 1997;39(89-99). DOI: https://doiorg.

proxy.queensu.ca/10.1111/j.1469-8749.1997.tb07390.x

68. Hempel MS. 1993. The neurological examination for toddler-age. (PhD Thesis). University of Groningen.

69. Morgan C, Crowle C, Goyen T, Hardman C, Jackman M, Novak I. Sensitivity and specificity of general movements assessment for diagnostic accuracy of detecting cerebral palsy early in an Australian context. J Paediatr Child Health. 2016;52:54-9. Available from:

https://proxy.queensu.ca/login?url=http://ovidsp.ovid.com?T=JS\&CSC=Y\&NEWS=N\&PAGE=fulltext\&D=med12\&AN=26289780

https://onlinelibrary.wiley.com/doi/abs/10.1111/jpc.12995https://onlinelibrary-wiley-com.proxy.queensu.ca/doi/pdf/10.1111/jpc.12995 DOI: https://dx.doi.org/10.1111/jpc.12995.

70. Morgan C, Romeo DM, Chorna O, Novak I, Galea C, Del Secco S. The pooled diagnostic accuracy of neuroimaging, general movements, and neurological examination for diagnosing cerebral palsy early in high-risk infants: a case control study. J. Clin. Med. 2019;8:1879. doi: $10.3390 / \mathrm{jcm} 8111879$

71. Dubowitz LMS, Dubowitz V, Mercuri E. The neurological assessment of the preterm and full-term newborn infant. Clinics in developmental medicine 148. 2nd ed. London, UK: MacKeith Press;1999

72. Oberg GK, Jacobsen BK, Jorgensen L. Predictive value of general movement assessment for cerebral palsy in routine clinical practice. Phys Ther. 2015;95(11):1489-95. Available from: https://proxy.queensu.ca/login?url=http://ovidsp.ovid.com?

T=JS\&CSC=Y\&NEWS=N\&PAGE=fulltext\&D=med11\&AN=26023214 DOI: https://dx.doi.org/10.2522/ptj.20140429

73. Seme-Ciglenecki, P. Predictive value of assessment of general movements for neurological development of high-risk preterm infants: comparative study. Croat Med J. 2003;44(6): 721-7. Available from: https://proxy.queensu.ca/login?url=http://ovidsp.ovid.com?

$T=J S \& C S C=Y \& N E W S=N \& P A G E=$ fulltext $\& D=\operatorname{med} 4 \& A N=14652886$

74. Illingworth RS. The development of the infant and young child: normal and abnormal. $9^{\text {th }}$ New York (NY): Churchill Livingstone; 1987.

75. Soleimani F, Badv RS, Momayezi A, Biglarian A, Marzban A. General movements as a predictive tool of the neurological outcome in term born infants with hypoxic ischemic encephalopathy. Early Hum Dev. 2015;91(8):479-82. Available from: https://proxy.queensu.ca/login? url=http://ovidsp.ovid.com?

$\mathrm{T}=\mathrm{JS} \& C S C=Y \& N E W S=N \& P A G E=$ fulltext\&D=med11\&AN=26070097https://www.sciencedirect.com/science/article/abs/pii/S0378378215001176? via\%3Dihub DOI: https://dx.doi.org/10.1016/j.earlhumdev.2015.05.007

76. Ellison P. The INFANIB, a reliable method for the neuromotor assessment of infants. Tucson, AZ, USA: Therapy Skill Builder; 1994.

77. Støen R, Boswell L, de Regnier R, Fjørtoft T, Gaebler-Spira D, Ihlen E, Labori C. The predictive accuracy of the general movement assessment for cerebral palsy: a prospective, observational study of high-risk infants in a clinical follow-up setting. J. Clin. Med. 2019;8:1790.

doi: $10.3390 / \mathrm{jcm} 8111790$

78. Cans, C. Surveillance of cerebral palsy in Europe: A collaboration of cerebral palsy surveys and registers. Surveillance of cerebral palsy in Europe (SCPE). Dev. Med. Child Neurol. 2000;42: 816-824

79. Sustersic B, Paro-Panjan D. Assessment of general movements in relation to neurologic signs at age two years. Pediatr Neurol. 2008;39(2):10812. DOI: https://dx.doi.org/10.1016/j.pediatrneurol.2008.05.00

80. van lersel PA, Bakker SC, Jonker AJ, Hadders-Algra M. Does perinatal asphyxia contribute to neurological dysfunction in preterm infants? Early Hum Dev. 2010;86(7):457-61. Available from: https://proxy.queensu.ca/login?url=http://ovidsp.ovid.com?

$\mathrm{T}=\mathrm{JS} \& C S C=Y \& N E W S=N \& P A G E=$ fulltext\&D=med7\&AN=20605570https://www.sciencedirect.com/science/article/abs/pii/S0378378210001246? via\%3Dihub DOI: https://dx.doi.org/10.1016/j.earlhumdev.2010.06.003

81. Ferrari F, Todeschini A, Guidotti I, Martinez-Biarge M, Roversi MF, Berardi A, et al. General movements in full-term infants with perinatal asphyxia are related to basal ganglia and thalamic lesions. J Pediatr. 2010;158(6):904-11. DOI:https://doi.org/10.1016/j.jpeds.2010.11.037

Page 13/15 
82. Prechtl HF, Ferrari F, Cioni G. Predictive value of general movements in asphyxiated fullterm infants. Early Hum Dev. 1993 Dec 15;35(2):91-120. Available from:https://proxy.queensu.ca/login?url=http://ovidsp.ovid.com?

$\mathrm{T}=\mathrm{JS} \& C S C=Y \& N E W S=N \& P A G E=$ fulltext\&D=med3\&AN=8143572https://www.sciencedirect.com/science/article/abs/pii/037837829390096D? via\%3Dihub

83. Moola S, Munn Z, Tufanaru C, Aromataris E, Sears K, Sfetcu R, et al. Chapter 7: Systematic reviews of etiology and risk. In: Aromataris E, Munn Z (Editors). Joanna Briggs Institute Reviewer's Manual. The Joanna Briggs Institute, 2017. Available from https://reviewersmanual.joannabriggs.org/

84. Levene ML, Kornberg J, Williams TH. The incidence and severity of post-asphyxial encephalopathy in full-term infants. Early Hum Dev. 1985;11(1):21-26. doi:10.1016/0378-3782(85)90115-x

85. El-Gilany, Abdel-Hady. What is case series? Asp Biomed Clin Case Rep. 2018 Aug 17;1(1):10-15. Available from: https://www.researchgate.net/publication/327449197_What_is_case_series

86. The centre for evidence-based medicine. Oxford centre for evidence-based medicine - levels of evidence. March 2009. Available from: https://www.cebm.net/2009/06/oxford-centreevidence-based-medicine-levels-evidence-march-2009/

87. Bednarek N, Mathur A, Inder T, Wilkinson J, Neil J, Shimony J. Impact of therapeutic hypothermia on MRI diffusion changes in neonatal encephalopathy. Neurology. 2012;78(18):1420-1427. DOI:10.1212/WNL.0b013e318253d589

\section{Figures}

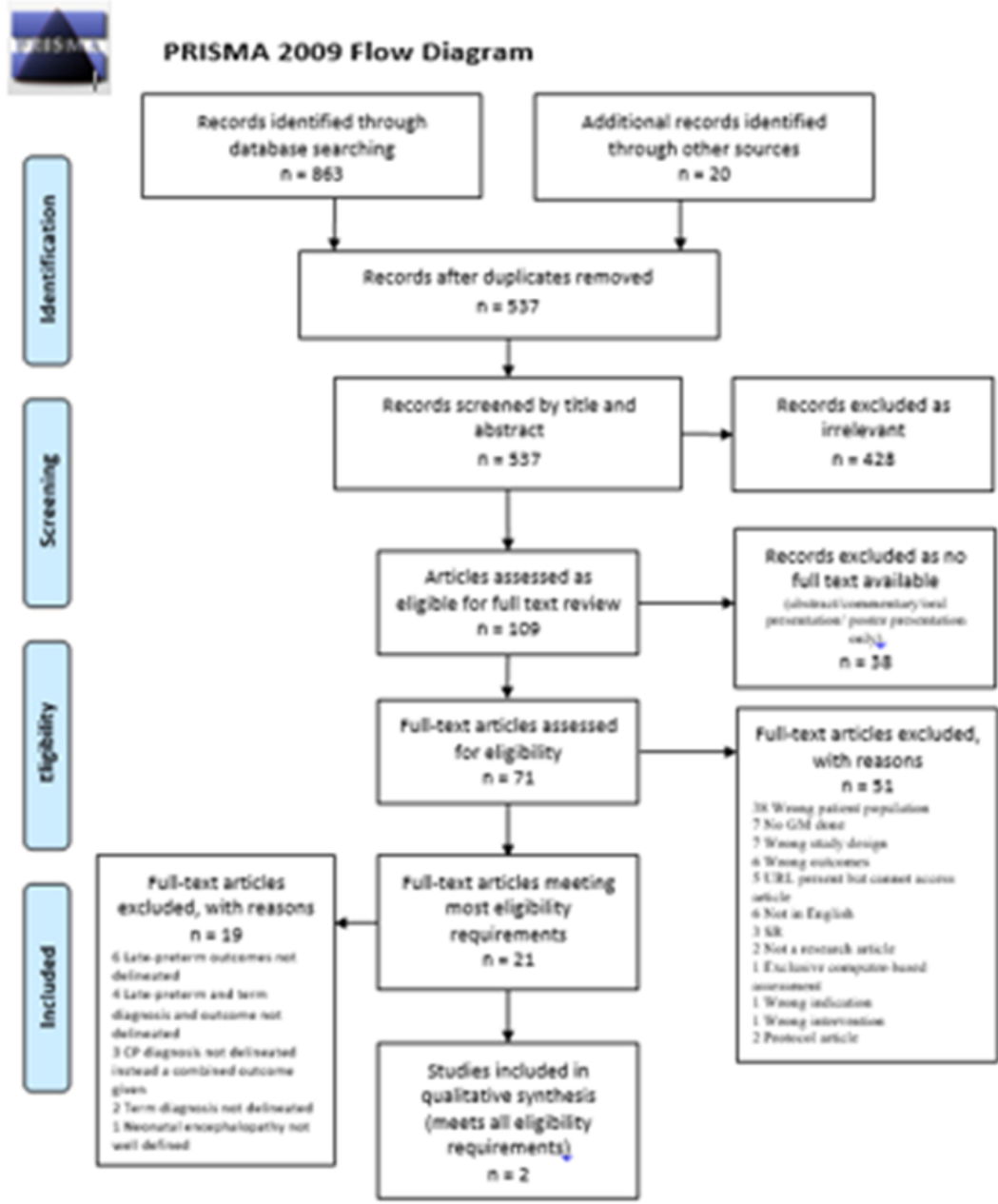


Flow chart for the selection of articles at different phases of the scoping review

\section{Supplementary Files}

This is a list of supplementary files associated with this preprint. Click to download.

- Additionalfile1ProtocolforGMAandNEinCP.pdf

- Additionalfile2proposal.docx

- Additionalfile3Allsearchstrategies.docx

- Additionalfile4TablesGMAandNEwithtrackchanges.docx

- Additionalfile5Table8Criticalappraisalwithtrack.docx

- PRISMAScRrevised.pdf 